\title{
Ámbito subjetivo de aplicación de los precedentes judiciales: un estudio en la jurisdicción constitucional en Colombia*
}

\author{
Fabio Enrique Pulido Ortiz* \\ Recibido: 21 de julio de 2017 • Aprobado: 23 de mayo de 2018 \\ https://doi.org/10.22395/ojum.v17n34a6
}

\section{RESUMEN}

El objetivo de este artículo es explicar el ámbito subjetivo de aplicación de la regla de precedente. Mediante el análisis de la estructura normativa de la regla de precedente se señala que una de sus principales funciones es definir los órganos y procedimientos para la aplicación de los precedentes judiciales. A partir de este análisis, se muestra que la definición del ámbito subjetivo de aplicación de la regla de precedente (es decir, el conjunto de órganos con la competencia de aplicar los precedentes judiciales) depende de la definición de la estructura de la jurisdicción. En este contexto, se concluye que la jurisdicción colombiana está constituida por un sistema centralizado y monista en el que la Corte Constitucional se instituye como órgano de cierre del sistema judicial en Colombia. En consecuencia, el ámbito subjetivo de los precedentes de la Corte Constitucional incluye a todos los órganos de la jurisdicción colombiana. En otras palabras, estos precedentes judiciales son precedentes verticales respecto de las decisiones de todas las cortes, tribunales y jueces que conforman la jurisdicción colombiana.

Palabras clave: precedentes judiciales; derecho constitucional; teoría del derecho; rama judicial; jurisdicción constitucional colombiana.

\footnotetext{
Este artículo forma parte de los resultados del proyecto de investigación Coordinación y autoridad en el Estado Constitucional de Derecho. Desafíos teóricos y prácticos en un contexto de fragmentación moral subvencionado por Agencia Nacional de Promoción Científica y Tecnológica del Ministerio de Ciencia, Tecnología e Innovación Productiva de la República Argentina (Picto 2016 0095).

** Abogado, Universidad Católica de Colombia, Bogotá, Colombia; magíster en Derecho, Universidad de Palermo, Buenos Aires, Argentina; doctor en Derecho, Universidad de Buenos Aires, Buenos Aires, Argentina; director del Departamento de Teoría Jurídica y Constitucional y de la Maestría en Derecho Constitucional de la Universidad de La Sabana, Bogotá, Colombia. Correo electrónico fabio.pulido@ unisabana.edu.co. Orcid: 0000-0002-1100-9962.
} 


\title{
Subjective scope of application of judicial precedents: a study in the constifutional jurisdiction in Colombia
}

\begin{abstract}
The purpose of this paper is to explain the subjective scope of application of the precedent rule. An analysis of the normative structure of the precedent rule indicates that one of its main functions is to define the organs and procedures for the application of judicial precedents. From this analysis, it is shown that the definition of the subjective scope of application of the precedent rule (i.e. the set of organs with the competence to apply judicial precedents) depends on the definition of the structure of the jurisdiction. In this context, it is concluded that Colombian jurisdiction is constituted by a centralized and monist system in which the Constitutional Court is instituted as the closing organ of the judicial system in Colombia. Consequently, the subjective scope of the precedents of the Constitutional Court includes all organs of Colombian jurisdiction. In other words, these judicial precedents are vertical precedents for the decisions of all the courts, tribunals and judges that make up Colombia's jurisdiction.
\end{abstract}

Keywords: judicial precedents; constitutional law; theory of law; judicial branch; Colombian constitutional jurisdiction.

\section{Âmbito subjetivo de aplicação dos precedentes judiciais: um estudo na jurisdição constitucional na Colômbia}

\section{RESUMO}

O objetivo deste artigo é explicar o âmbito subjetivo de aplicação da regra de precedente. Por meio da análise da estrutura normativa da regra de precedente assinala-se que uma de suas principais funções é definir os órgãos e os procedimentos para a aplicação dos precedentes judiciais. A partir dessa análise, mostra-se que a definição do âmbito subjetivo de aplicação da regra de precedente (ou seja, o conjunto de órgãos com a competência para aplicar os precedentes judiciais) depende da definição da estrutura da jurisdição. Nesse contexto, conclui-se que a jurisdição colombiana está constituída por um sistema centralizado e monista no qual a Corte Constitucional é instituída como órgão de fechamento do sistema judicial na Colômbia. Consequentemente, o âmbito subjetivo dos precedentes da Corte Constitucional inclui todos os órgãos da jurisdição colombiana. Em outras palavras, esses precedentes judiciais são precedentes verticais com respeito às decisões de todas as cortes, tribunais e juízes que formam a jurisdição colombiana.

Palavras-chave: precedentes judiciais; direito constitucional; teoria do direito; ramo judicial; jurisdição constitucional colombiana. 


\section{INTRODUCCIÓN}

Los precedentes judiciales (en adelante PJ) son normas generales y abstractas creadas por los jueces en sus providencias. Los PJ pueden cumplir dos funciones normativas: por una parte, una función persuasiva al guiar la conducta de los individuos cuando estos están convencidos de la corrección del PJ o, en todo caso, están de acuerdo con él; y, por otra parte, una función normativo-autoritativa, al exigir determinadas conductas, aun si los individuos no están de acuerdo (Lamond, 2014 y Bronaugh, 1987). Esto quiere decir que los ordenamientos jurídicos pueden otorgar autoridad normativa a los PJ mediante la creación o reconocimiento de la regla o doctrina del PJ vinculante (RP). La regla de precedente (en adelante RP), por tanto, es aquella regla de los ordenamientos jurídicos que define y regula la función normativo-autoritativa de los PJ.

En el conocido estudio comparado de MacCormick y Summers (1997) se señala que, para definir la forma en que opera la RP, hay que investigar el contexto institucional en que se usan los PJ y, en particular, la estructura de la rama judicial. Esto es así, toda vez que esta estructura determina el ámbito subjetivo de la RP, es decir el conjunto de individuos y órganos cuyas decisiones están sujetas a la autoridad de los PJ (Taruffo, 1997). De acuerdo con esto, la cuestión que se aborda en este artículo consiste en definir el ámbito subjetivo de aplicación de la RP en la jurisdicción constitucional colombiana.
El trabajo se divide en dos partes. En la primera se explica el ámbito subjetivo de aplicación de los PJ, es decir, el conjunto de individuos y órganos cuyas decisiones están sujetas a la autoridad de los PJ. En la segunda se describe la organización de la jurisdicción constitucional colombiana, precisando su modelo organizativo y las relaciones entre órganos de cierre y órganos de instancia. A partir de estas consideraciones, se precisan las relaciones de verticalidad y horizontalidad del precedente en la jurisdicción constitucional en Colombia.

\section{1. ÁMBITO SUBJETIVO DE APLICACIÓN DE LA REGLA DE PRECEDENTE}

En relación con las normas jurídicas es posible diferenciar entre su ámbito de aplicación y su fuerza. El ámbito de aplicación de las normas jurídicas se refiere al conjunto de potenciales decisiones afectadas, y la fuerza a las condiciones establecidas en el ordenamiento jurídico para que una norma jurídica pueda considerarse vinculante (Alexander, 2012). En este orden de ideas, el ámbito de aplicación de un PJ se refiere, por tanto, al conjunto de acciones reguladas por el PJ (ámbito objetivo de aplicación) y los sujetos vinculados a su autoridad (ámbito subjetivo de aplicación). Teniendo en cuenta el objetivo de este artículo se dejará de lado el estudio de la fuerza y del ámbito objetivo de aplicación de los PJ, para concentrarse en el ámbito subjetivo de aplicación.

Para comprender el ámbito subjetivo de aplicación de los PJ es necesario realizar 
una explicación adicional. A partir de la influyente obra de H. L. A. Hart (1994) se ha mostrado que los ordenamientos jurídicos contemporáneos están compuestos por dos tipos de reglas: las reglas primarias y las reglas secundarias. Las reglas primarias son aquellas que exigen la realización (o no realización) de determinados tipos de acciones. Estas reglas se caracterizan por contener los siguientes elementos: a) el contenido de la regla es el tipo de acción (esto es una descripción de la clase de acciones humanas) regulada por la norma jurídica; b) el carácter o calificación deóntica de la acción regulada, a saber, la clasificación de la acción definida como obligatoria, facultativa o prohibitiva y c) los sujetos vinculados, es decir los destinatarios de la acción exigida. Los sujetos vinculados, en otras palabras, son los individuos que deben realizar la conducta exigida, prohibida o facultada por la norma'.

Veamos la estructura de las reglas primarias mediante un ejemplo. De acuerdo con un reiterado $\mathrm{PJ}$ de la Corte Constitucional (sentencias T-096 de 2016 y T-056 de 2015), las entidades promotoras de salud (EPS) están obligadas $(\mathrm{O})$ a suministrar (S) pañales (P) a las personas de la tercera edad (A). Según este ejemplo, la regla jurídica del PJ de la sentencia tiene los siguientes elementos: el caso está conformado por la descripción de una clase de objetos (P) y una clase de acciones (S). El carácter de la norma es de obligatorie-

Sobre el particular véase Von Wright (1963) y Alchourron y Buligyn (1971). Un análisis de estas cuestiones en la regla del precedente ha sido presentado en Pulido (2018). dad, es decir, que las EPS deben realizar la conducta "suministrar pañales (SP)". Y los sujetos normativos son aquellos individuos que están obligados a SP, es decir, todos aquellos individuos que sean EPS.

Las reglas secundarias, por otro lado, son aquellas normas de los ordenamientos jurídicos cuya finalidad es definir cómo identificar, crear, modificar, derogar o aplicar otras reglas. Así, según Hart, existen tres tipos de reglas secundarias: de cambio, de adjudicación y de reconocimiento. Las reglas de cambio son las que establecen las formas y procedimientos para modificar las reglas primarias. Las reglas de adjudicación son las que establecen quién y cómo se resuelven los conflictos en la aplicación de las reglas primarias. Por último, la regla de reconocimiento establece los criterios de pertenencia y de identificación de normas pertenecientes y aplicables en un sistema jurídico (Hart, 1994, pp. 79-89).

A partir de esta breve presentación de la diferencia entre reglas primarias y secundarias, y limitándonos a la explicación de la RP, es posible resaltar tres cuestiones. Primero, la RP es una regla secundaria de los ordenamientos jurídicos cuya función es definir la función normativa de los precedentes judiciales. Recuérdese que los PJ pueden, en general, cumplir dos funciones normativas. Pueden, por un lado, cumplir una función normativa-autoritativa al exigir determinadas conductas de forma autoritativa; es decir, exigir que determinadas acciones o actos sean realizados con independencia de las consideraciones de los sujetos acerca de 
la corrección de esas conductas o actos. Pueden, por otro lado, cumplir una función normativa-persuasiva acerca de la realización de determinadas acciones o actos; es decir, servir de razones de apoyo a los individuos respecto de acciones o actos respecto de los cuales ellos están de acuerdo (Levenbook, 2000, Lamond, 2014 y Bronaugh, 1987). De esta manera, corresponde a la RP definir en cada ordenamiento jurídico el tipo de función normativa de los $\mathrm{PJ}^{2}$.

Segundo, en tanto regla secundaria, la RP cumple — por lo menos — las siguientes funciones: a) define el funcionamiento normativo de los PJ; b) precisa los criterios a partir de los cuales se identifican los PJ; c) establece los órganos y procedimientos mediante los cuales se crean, modifican, derogan los PJ y d) señala las condiciones de aplicación de los PJ.

$\mathrm{Y}$, tercero, el reconocimiento de la RP es una propiedad contingente de los ordenamientos jurídicos. Es decir, la existencia de la RP en los ordenamientos jurídicos específicos depende de las convenciones jurídicas existentes (lo que no significa, desde luego, que no existan razones que justifiquen su reconocimiento o rechazo).

En síntesis, la RP es una regla secundaria que, además de hacer parte de la regla de reconocimiento, contempla reglas de cambio y de adjudicación de los PJ. Las reglas de cambio son reglas de compe-

2 Puede ocurrir, incluso, que como regla secundaria se prohíba el uso de los PJ o de algunos de ellos. tencia ${ }^{3}$ que autorizan a determinados individuos para que introduzcan nuevas reglas, las modifiquen o las deroguen. Una regla de cambio tiene una estructura como la siguiente:
A, mediante el procedimiento $\mathrm{P}$, es competente para crear, derogar o mo- dificar $\mathrm{R}$.

Así las cosas, y en tanto regla de cambio, la RP define las variables A, P y R en relación con los PJ. La variable A está integrada por aquellos órganos judiciales (J) que tienen competencia para crear, modificar o derogar PJ. La variable R está conformada por todas y cada una de las normas que, de acuerdo con RP, son consideradas PJ. En este orden de ideas, la RP como regla de cambio (en adelante RPC) tiene la siguiente estructura:
RPC: J1, mediante el procedi- miento $\mathrm{P}$, es competente para crear, derogar o modificar PJ.

Por otro lado, las reglas de adjudicación son reglas de competencia que establecen los órganos que tienen la potestad de definir (autoritativamente) si una regla debe o no aplicarse a determinada situación. Las reglas de adjudicación definen, además, los procedimientos y formas

3 La noción de regla de competencia puede verse en Hart (1994). Se está dejando afuera de este análisis la cuestión de si las reglas de competencia deben ser caracterizadas como reglas prescriptivas, reglas permisivas o reglas constitutivas. Una presentación general de esta cuestión puede verse en Moreso y Vilajosana (2004). Una revisión crítica de la noción defendida por Hart puede verse en Atienza y Ruiz Manero (1996, p. 45-76). 
mediante las cuales se deben aplicar las reglas. Estas reglas tienen la siguiente estructura:

\section{$\mathrm{A}$, mediante el procedimiento $\mathrm{P}$, es competente para aplicar R.}

Como se ve, la regla de adjudicación define los órganos o individuos que deben aplicar las reglas y los procedimientos para ello. Así las cosas, la RP — como regla de adjudicación (en adelante RPA) - presenta la siguiente estructura.

\section{RPA: Al, mediante el procedi- miento $\mathrm{P}$, es competente para aplicar PJ.}

Estas consideraciones son suficientes para mostrar que el ámbito subjetivo de aplicación de la RP se refiere al conjunto de órganos (Al) a los que la RPA otorga la competencia para aplicar PJ en el ordenamiento jurídico respectivo. Al respecto es posible realizar tres precisiones.

En primer lugar, no existe impedimento conceptual alguno para que J1 y Al sean el mismo órgano (es decir, el mismo juez). Esto ocurre en los casos en que la RP exige que los jueces sigan sus propios precedentes. En estas circunstancias, $\mathrm{Jl}$-quien de acuerdo con RPC tiene la competencia de crear PJ—y Al — quien de acuerdo con RPA debe aplicar PJ— son el mismo órgano judicial. Acá, sin embargo, surge la cuestión acerca de en qué sentido se puede afirmar que el mismo órgano que crea la regla sea el que debe aplicarla. En este contexto, para que se pueda afirmar que existe RP, debe ser po- sible diferenciar entre: a) las condiciones para crear, modificar y derogar los PJ y b) las condiciones para aplicarlos. En estos términos la existencia del autoprecedente (es decir el deber de los jueces de aplicar sus propios precedentes) depende de que se pueda diferenciar RPA de RPC ${ }^{4}$.

En segundo lugar, se debe señalar que mientras Jl está constituido necesariamente por un órgano judicial, Al puede referirse a otro tipo de órganos. En efecto, una característica necesaria de los PJ es que son normas jurídicas creadas (o por lo menos reconocidas) por los órganos judiciales. Por el contrario, los órganos que tienen la competencia de aplicarlos pueden ser más amplios e incluir, por ejemplo, órganos administrativos. Esto puede verse en la forma como se ha desarrollado la RP en el derecho constitucional colombiano en donde se ha reconocido que los PJ deben ser aplicados no solo por los jueces, sino también por las autoridades administrativas (Corte Constitucional, Sentencia T-430 de 2014).

En tercer lugar, en la caracterización del ámbito subjetivo de aplicación de la RP es necesario diferenciar entre: a) los individuos (y órganos) que deben realizar las

4 Estas características no son, desde luego, exclusivas de la RP. En los ordenamientos jurídicos es posible encontrar varias situaciones en las que el órgano de producción de normas es el mismo órgano encargado de aplicarlas o seguirlas. En el derecho colombiano, por ejemplo, la validez de las leyes se condiciona al complimiento de las reglas del procedimiento parlamentario que son, a su vez, creadas por el Congreso de la República, es decir, por aquel órgano que debe seguirlas como condición de validez de las leyes (Ley 5, 1992). 
conductas exigidas por los PJ, es decir el ámbito subjetivo de aplicación de cada uno de los PJ y b) los órganos encargados de aplicar los PJ, esto es, el ámbito subjetivo de aplicación de la RPA en tanto regla secundaria de adjudicación. Para explicarlo volvamos con el ejemplo ya mencionado. El PJ establece que las EPS están obligadas a suministrar pañales a las personas de la tercera edad. Y, por otro lado, la RP en el derecho colombiano define que los PJ deben ser aplicados por los jueces y las autoridades administrativas en el marco de sus funciones. Imaginemos que Antonio es una persona de la tercera edad a la que una EPS le ha negado el suministro de pañales. El sujeto vinculado al PJ (esto es quien debe realizar la acción exigida) es la EPS. Pero el PI puede ser aplicado, según el caso, por un juez (por ejemplo, mediante una sentencia de tutela) o por una autoridad administrativa (por ejemplo, el Ministerio de Salud en el marco de una queja administrativa).

Según lo explicado, las reglas primarias están conformadas por a) el contenido (el caso regulado); b) el carácter o calificación deóntica y c) los sujetos vinculados, es decir los destinatarios de la acción exigida. Por otra parte, las reglas de adjudicación están conformadas por a) el órgano competente; b) el procedimiento y c) el tipo de normas que deben ser aplicadas. En este orden de ideas, y siguiendo con el ejemplo, mientras las EPS hacen parte de los sujetos vinculados al PJ (en tanto regla primaria), los jueces y el Ministerio son los órganos competentes para aplicar el PJ (es decir, forman parte de los órganos definidos en la RPA). Así las cosas, en la explicación del ámbito subjetivo de la RP, es necesario diferenciar entre los sujetos vinculados a cada uno de los PJ y los órganos encargados de aplicar los PJ en virtud del contenido de la RPA.

En conclusión, el ámbito subjetivo de aplicación de la RP se refiere al conjunto de órganos Al a los que la RPA otorga la competencia para aplicar el PJ en el ordenamiento jurídico respectivo. Si bien es cierto que, como vimos, Al puede incluir tanto órganos judiciales como administrativos, resulta sin lugar a dudas fundamental establecer el conjunto de órganos judiciales designados por la RPA para la aplicación de los PJ. En esta tarea suele distinguirse entre precedente vertical aquellos PJ que provienen de sentencias de un juez o tribunal de jerarquía superior-, precedente horizontal —aquellos PJ que provienen de sentencias de jueces o tribunales de la misma jerarquía- y autoprecedente - los PJ creados por los mismos jueces o tribunales que tienen que aplicarlo- (Cross y Harris, 2012; Magaloni, 2001 y Gascón, 2012).

\section{EL MODELO DE JURISDICCIÓN COLOMBIANA $Y$ LAS VARIABLES VERTICAL/HORIZONTAL DEL PRECEDENTE}

En el apartado anterior se indicó que el ámbito subjetivo de aplicación de la RP se refiere al conjunto de órganos Al que deben aplicar los PJ. Alrededor de esta cuestión (es decir los órganos o sujetos encargados de aplicar los PJ) tradicionalmente se ha diferenciado entre precedente vertical y precedente horizontal. Para definir estas variables es necesario deter- 
minar la estructura de jurisdicción, a partir de la cual es posible definir la jerarquía de los órganos judiciales que crean los PJ en relación con los órganos judiciales encargados de aplicarlos (Dobbins, 2010 y Taruffo, 1997). De acuerdo con esto, en las siguientes líneas se presenta la estructura de la jurisdicción en Colombia para luego definir las variables vertical y horizontal del precedente constitucional.

\subsection{La estructura de la jurisdicción en Colombia}

Por jurisdicción se ha entendido, tradicionalmente, como la función del Estado de administrar justicia, es decir, la capacidad de definir autoritativamente las controversias acerca de la adecuada aplicación del derecho (Azula, 2006). Los Estados contemporáneos, para desarrollar esta función, establecen un conjunto de funcionarios encargados de realizar esta tarea. En estos términos, la jurisdicción se refiere, por una parte, a la función de administrar justicia y, por la otra, al conjunto de individuos y órganos encargados de realizar esta función, es decir, la rama judicial del poder público 5 .

Teniendo en cuenta que la caracterización de precedente vertical y horizontal depende fundamentalmente de la forma como está organizada la jurisdicción, veamos cómo se conforma la rama la rama judicial en Colombia. La Constitución colombiana ha definido que la rama judicial está conformada por cuatro jurisdicciones ${ }^{6}$ :

5 Para una diferencia entre función y órgano véase Guastini (2001).

6 Acá se describirán las jurisdicciones permanentes. Más adelante se mostrará la inserción de la jurisdicción especial de paz (JEP) en la estructura
1) La jurisdicción ordinaria encargada del juzgamiento de todos los asuntos civiles, penales, laborales y de familia (Constitución Política de Colombia, artículos 234 y 235).

2) La jurisdicción contencioso-administrativa que se encarga del juzgamiento de las controversias y litigios administrativos originados en las entidades públicas y en las personas privadas que desempeñan funciones públicas (artículos 236 y 237 de la Constitución Política de Colombia).

3) La jurisdicción disciplinaria encargada del control disciplinario en la rama judicial (Constitución Política de Colombia, artículo 254, artículo 75 de la Ley 270 de 1996).

4) La jurisdicción constitucional en Colombia ${ }^{7}$ encargada de dos asuntos es-

de la rama judicial. Además, debe advertirse que los artículos 246 y 247 consagran, además de las jurisdicciones mencionadas, a las jurisdicciones especiales. El artículo 246 establece que "las autoridades de los pueblos indígenas podrán ejercer funciones jurisdiccionales dentro de su ámbito territorial, de conformidad con sus propias normas y procedimientos, siempre que no sean contrarios a la Constitución y leyes de la República". El artículo 247, por su parte, define que "la ley podrá crear jueces de paz encargados de resolver en equidad conflictos individuales y comunitarios". De esta manera, y de acuerdo con el título VIII de la CP, la rama judicial está conformada por la jurisdicción ordinaria, la contencioso-administrativa, la constitucional, las especiales, la Fiscalía General de la Nación y el Consejo Superior de la Judicatura.

7 Debe advertirse que, de acuerdo con un criterio funcional de justicia constitucional, ella comprende no solamente el control de constitucionalidad de las leyes, sino todas las 
pecíficos: (1) control abstracto de constitucionalidad de normas con rango de ley y (2) control concreto mediante la revisión de las decisiones judiciales relacionadas con la acción de tutela de los derechos constitucionales.

Cada una de las jurisdicciones plantea una estructura jerárquica y piramidal con jueces y tribunales encargados de resolver los asuntos en primera y segunda instancia, y un órgano de cierre con la función de "asegurar la coherencia del ordenamiento legal, gracias a la unificación de criterios de interpretación de la ley, para de esa manera, lograr la realización del derecho objetivo y asegurar el respeto de los principios de igualdad y legalidad" (2003, p. 199). Así las cosas, la Corte Suprema de Justicia es el órgano de cierre de la jurisdicción ordinaria; mientras que los tribunales superiores del distrito judicial, los jueces del circuito y los jueces municipales (y promiscuos) se desempeñan como órganos de instancia. Para la jurisdicción administrativa, el Consejo de Estado es el órgano de cierre, mientras que los tribunales administrativos y los jueces administrativos se desempeñan como órganos de instancia. La Comisión Nacional de Disciplina Judicial se encuen-

acciones y recursos judiciales destinados a asegurar la supremacía de la Constitución. No obstante, para los propósitos de este trabajo, se empleará un criterio orgánico para la definición de la jurisdicción constitucional. De acuerdo con este criterio - empelado en los artículos 239 a 245 de la Constitución Política- forman parte de la jurisdicción constitucional: la Corte Constitucional y todos los jueces encargados de decidir acciones de tutela para la protección de los derechos fundamentales. tra definida como el órgano de cierre de la jurisdicción disciplinaria en la que los consejos seccionales de la judicaturas desempeñan como órganos de instancia ${ }^{8}$. Por último, en la jurisdicción constitucional se le encargó a la Corte Constitucional dos funciones: por un lado, el control abstracto de constitucionalidad de normas con rango de ley y actos reformatorios de la Constitución y por el otro, funciones de órgano de cierre mediante la revisión de las decisiones judiciales relacionadas con la acción de tutela de los derechos constitucionales (artículo 241 de la Constitución Política de Colombia).

Ahora bien, desde esta perspectiva estructural, una adecuada descripción de la organización de la jurisdicción en aquellos

8 Debe tenerse en cuenta que, originalmente, la Constitución Política contemplaba que el órgano de cierre de la jurisdicción disciplinaria era la Sala Disciplinaria del Consejo Superior de la Judicatura. Sin embargo, el artículo 19 del Acto legislativo 2 de 2015, que adicionó el artículo 257A a la Constitución Política, define que "la Comisión Nacional de Disciplina Judicial ejercerá la función jurisdiccional disciplinaria sobre los funcionarios y empleados de la rama judicial" y que "podrá haber comisiones seccionales de disciplina judicial integradas como lo señale la ley". Por otra parte, la Corte Constitucional declaró inexequibles las modificaciones planteadas en el Acto legislativo 2 de 2015 en relación con las modificaciones a las competencias de gobierno judicial en cabeza del Consejo Superior de la Judicatura (Sentencia C-285 de 2016). No obstante, están vigentes las reformas constitucionales en la estructura de la jurisdicción disciplinaria, es decir la creación de la Comisión Nacional de Disciplina Judicial (que remplazará las funciones jurisdiccionales de la Sala Jurisdiccional de la Judicatura) y la posibilidad de crear comisiones seccionales de disciplina judicial (que remplazarán a los consejos seccionales de la judicatura). 
ordenamientos jurídicos que establecen el control judicial de la Constitución, depende de la articulación de la jurisdicción constitucional (encargada de ese control) con las otras jurisdicciones (Taruffo, 1997). Al respecto, existen dos modelos: el centralizado y el descentralizado. El modelo centralizado define una estructura de jurisdicción monista, en tanto no separa orgánicamente los jueces encargados de realizar el control constitucional del resto de jueces de la rama judicial. El modelo descentralizado, por el contrario, establece una estructura jurisdiccional dualista, pues divide la rama judicial entre aquellos que desempeñan competencias de control constitucional y aquellos que desempeñan las otras funciones jurisdiccionales (Ferreres, 2005; 2011).

La estructura jurisdiccional dualista puede ser más o menos rígida, según dos variables: la pureza y la autonomía. La pureza depende de si el control constitucional abstracto es la única competencia del tribunal constitucional. La autonomía depende del grado en que el tribunal constitucional está desligado de la jurisdicción ordinaria. Es decir, la estructura dualista será más autónoma en cuanto menor sea la vinculación del tribunal constitucional con la jurisdicción ordinaria. Por ello, si existe algún tipo de recurso o acción judicial mediante los cuales el tribunal constitucional revise las decisiones de la jurisdicción ordinaria, el sistema pierde su autonomía (Ferreres, 2005; 2011).

El diseño original de la Constitución Política de Colombia planteaba un modelo en el que las jurisdicciones ordinaria, contencioso-administrativa y disciplinaria (con órganos de cierre específicos e independientes) coexistían con una jurisdicción constitucional (cuyo órgano de cierre es la Corte Constitucional). Dentro de este diseño, la función jurisdiccional en materia de acción de tutela es ejercida por jueces, tribunales y cortes que, orgánicamente, pertenecen a otras jurisdicciones pero que son competentes para conocer las acciones de tutela9?. Esto significa que estos jueces, tribunales y cortes forman parte de sus respectivas jurisdicciones (con las competencias específicas de cada una de ellas) pero también ejercen funciones de control constitucional concreto para la protección de los derechos fundamentales. Por lo tanto, mediante la revisión de las sentencias de tutela se establece un vínculo entre la Corte Constitucional y los jueces que forman parte orgánica de la jurisdicción ordinaria, quienes siempre que conocen de acciones de tutela conforman funcionalmente la jurisdicción constitucional en materia de derechos fundamentales (con la Corte Constitucional como órgano de cierre). Por lo anterior, corporaciones judiciales que en la jurisdicción ordinaria cumplen funciones de órganos de cierre, en materia de tutela se desempeñan como órga-

9 Inicialmente, los órganos judiciales pertenecientes a la jurisdicción disciplinaria eran competentes para conocer de procesos de tutela. Sin embargo, la Comisión Nacional de Disciplina Judicial y las comisiones seccionales de disciplina judicial no serán competentes para conocer de acciones de tutela. Sin embargo, el artículo 19 del Acto legislativo 2 de 2015 estableció que "la Comisión Nacional de Disciplina Judicial y las comisiones seccionales de disciplina judicial no serán competentes para conocer de acciones de tutela". 
nos de instancia ${ }^{10}$

De esta manera, el modelo de la jurisdicción constitucional planteado por la Constitución colombiana no es autónomo porque mediante la revisión de las sentencias de tutela se establece un vínculo funcional entre el tribunal constitucional y el resto de jurisdicciones. Tampoco es puro porque, además del control abstracto de constitucionalidad, la Corte Constitucional conoce, mediante la revisión de sentencias de tutela, de casos concretos sobre la violación de derechos constitucionales. Podría pensarse que, a pesar de la falta de pureza del sistema de jurisdicción constitucional colombiano, la autonomía está garantizada porque, primero, la vinculación con los jueces de las otras jurisdicciones se da vía acción de tutela y, segundo, porque la Corte Constitucional es órgano de cierre de la jurisdicción constitucional que es en definitiva independiente del resto de jurisdicciones.

Sin embargo, la práctica jurídica colombiana ha configurado una organización judicial monista con un solo órgano de cierre, al aceptarse que la Corte Constitucional revise las decisiones judiciales ordinarias mediante la admisión de la procedibilidad de la acción de tutela contra sentencias. En efecto, mediante la acción de tutela contra sentencias de los órganos de cierre, se diluye el principio de separación entre la jurisdicción ordinaria y la constitucional (propio de los sistemas descentralizados), y se instituye la Corte

10 Para estudios sobre la jurisdicción constitucional en Colombia, véanse Cifuentes (2002), Quinche (2013) y Pulido (2015).
Constitucional como máximo órgano judicial de las jurisdicciones en Colombia (Pulido, 2015).

Este hecho explica la importancia que ha tenido en la práctica jurídica colombiana la discusión acerca de la procedibilidad de la acción de tutela contra providencias judiciales. La tutela contra sentencias se ha convertido en un mecanismo para asegurar que las decisiones de las diferentes jurisdicciones se incorporen al desarrollo de la jurisdicción constitucional (Bernal, 2005). Esta doctrina, además, se ha constituido en el principal mecanismo de disciplina o monitoreo para asegurar que las decisiones de los diferentes órganos judiciales sigan los PJ de la Corte Constitucional. Sobre este último aspecto, vale la pena destacar que, de acuerdo con la Corte Constitucional, las decisiones judiciales que desconocen los PJ incurren en un defecto sustantivo que hace procedente la acción de tutela y su eventual anulación mediante este mecanismo. En palabras de la Corte Constitucional (Sentencia T-102 de 2014), el defecto sustantivo aparece:

Cuando la autoridad jurisdiccional (i) aplica una disposición en el caso que perdió vigencia por cualquiera de la razones previstas por la normativa, por ejemplo, su inexequibilidad; (ii) aplica un precepto manifiestamente inaplicable al caso, por ejemplo porque el supuesto de hecho del que se ocupa no tiene conexidad material con los presupuestos del caso; (iii) a pesar del amplio margen hermenéutico que la Constitución le reconoce a las autoridades judiciales, realiza una 
contraevidente -interpretación contra legem- o claramente irrazonable o desproporcionada; (iv) se aparta del precedente judicial -horizontal o verticalsin justificación suficiente; o (v) se abstiene de aplicar la excepción de inconstitucionalidad ante una violación manifiesta de la Constitución, siempre que su declaración haya sido solicitada por alguna de las partes en el proceso. (Negrilla en el original).

En definitiva, mediante la acción de tutela contra sentencias de los órganos de cierre, se diluye el principio de separación entre la jurisdicción ordinaria y la constitucional de los sistemas descentralizados y, en cambio, se plantea un sistema centralizado y monista, donde la Corte Constitucional se instituye como órgano de cierre del sistema judicial en Colombia. Mediante la revisión de las sentencias de tutela (en especial por la procedencia de esta acción en contra de las providencias judiciales), por lo tanto, la Corte Constitucional se convierte en el órgano de cierre del sistema judicial colombiano y, además, se le ofrece como un mecanismo de disciplina jurisprudencial a las demás jurisdicciones y órganos de la rama judicial (véanse las figuras 1 y 2).

\subsection{El ámbito subjetivo de aplicación de los precedentes judiciales y la inserción de la jurisdicción especial para la paz}

El 24 de noviembre de 2016, el Gobierno de la República de Colombia y las Fuerzas Armadas Revolucionarias de Colombia (FARC) suscribieron el Acuerdo final para

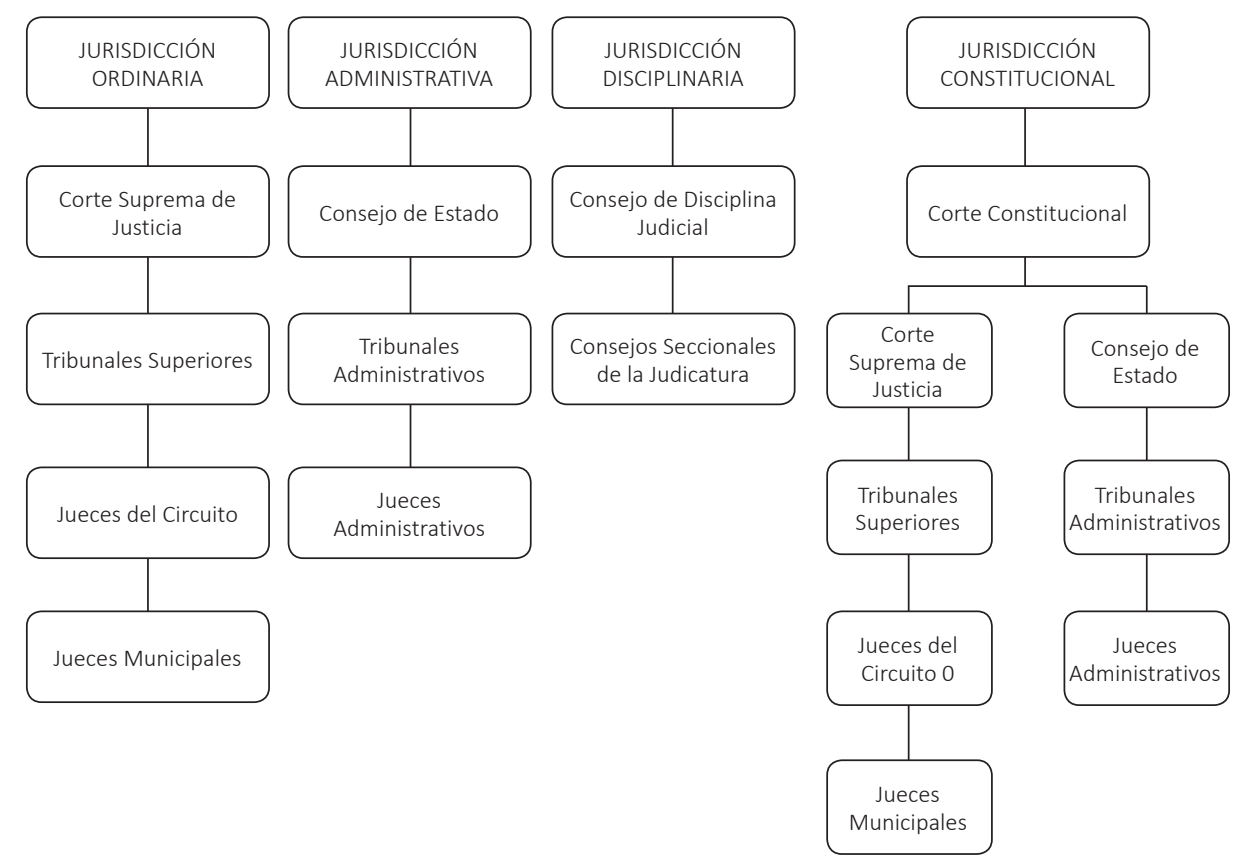

Figura 1. La jurisdicción pluralista en Colombia (sin tutela contra sentencias) 
la terminación del conflicto y la construcción de una paz estable y duradera. El Congreso de la República, por su parte, aprobó el Acto legislativo 1 de 2016 por medio del cual estableció los instrumentos jurídicos para la implementación del acuerdo. En el artículo $1^{\circ}$ del Acto legislativo se estableció un "procedimiento legislativo especial para la paz" con la intención de "agilizar y garantizar la implementación" del acuerdo. Por medio de este mecanismo, se definió un proceso abreviado para la aprobación de leyes y actos legislativos. En este contexto, se estableció un meca-

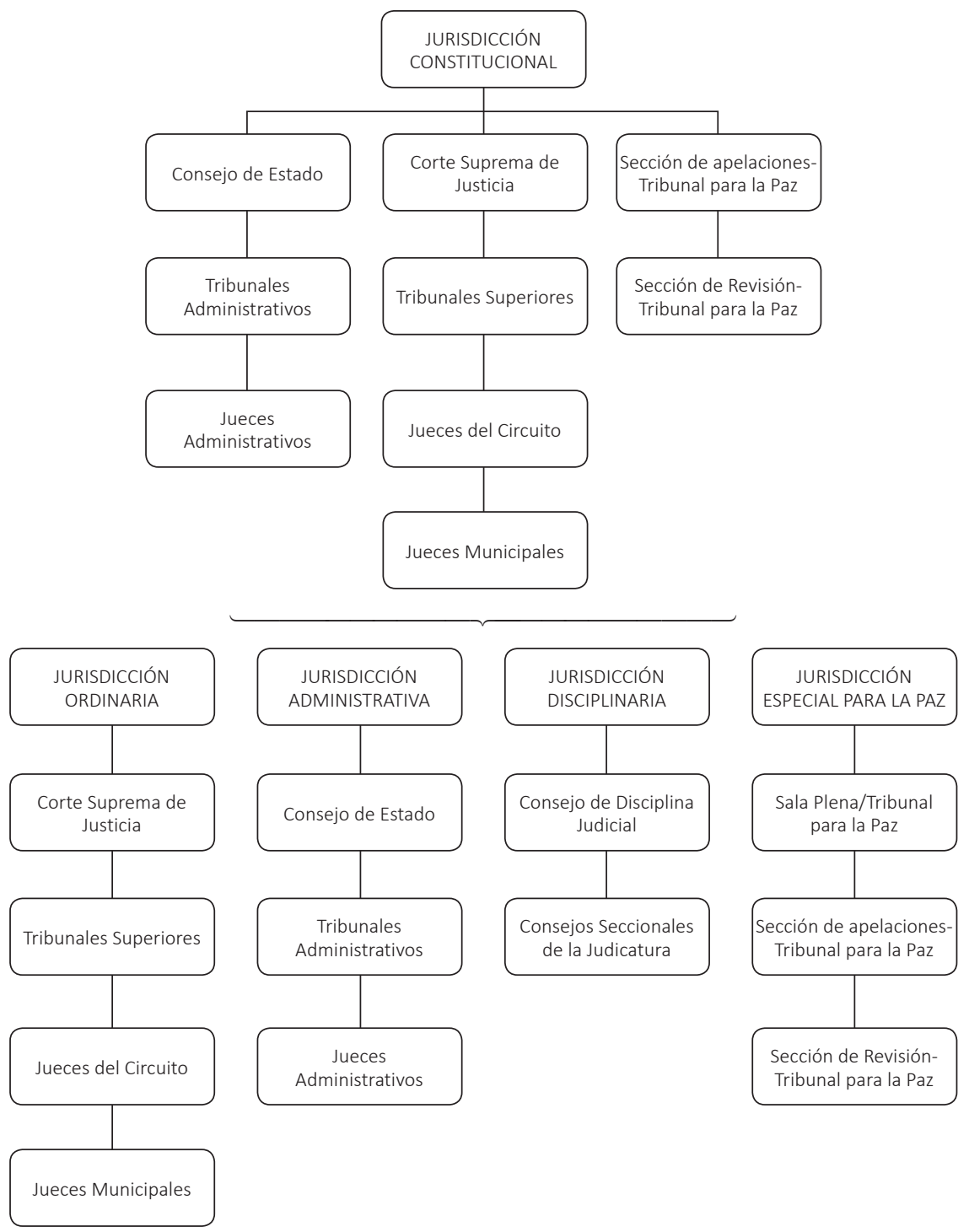

Figura 2. La jurisdicción monista en Colombia (con tutela contra sentencias) 
nismo abreviado de reforma constitucional: los actos legislativos fast track"1.

Por medio del Acto legislativo fast track 01 de 2017 se creó un nuevo título transitorio de la Constitución. Específicamente, en el capítulo II de este Título se estableció la jurisdicción especial para la paz (JEP) cuyos propósitos son:

Satisfacer el derecho de las víctimas a la justicia; ofrecer verdad a la sociedad colombiana; proteger los derechos de las víctimas; contribuir al logro de una paz estable y duradera; y adoptar decisiones que otorguen plena seguridad jurídica a quienes participaron de manera directa o indirecta en el conflicto armado.

Ahora bien, de conformidad con el artículo $5^{\circ}$ transitorio, y de acuerdo con los propósitos de este trabajo, deben destacarse las siguientes características de la JEP: 1) Autonomía y preferencia: la JEP debe tener "un régimen legal propio, con autonomía administrativa, presupuestal y técnica" y además "conocerá de manera preferente" los asuntos de su competencia "sobre todas las demás jurisdicciones". 2) Transitoriedad: la JEP "administrará justicia de manera transitoria" sobre "las conductas cometidas con anterioridad al 1 de diciembre de 2016". De acuerdo con el artículo 15 transitorio, "el plazo para la conclusión de las funciones de la JEP (...) será de diez años contados a partir de la entrada efectiva en funcionamiento de la

11 Para un estudio de los cambios en la estructura del Estado colombiano como consecuencia de los actos legislativo fast track, véanse Barreto (2017) y Pulido (2016). totalidad de las salas y secciones de la JEP, y un plazo posterior de cinco años más para concluir su actividad jurisdiccional, plazo este último que de ser necesario podrá ser prorrogado mediante ley, para concluir su actividad, a solicitud de los magistrados de la JEP". 3) Competencia: la JEP conocerá de las conductas que hayan sido realizadas "por causa, con ocasión o en relación directa o indirecta con el conflicto armado, por quienes participaron en el mismo, en especial respecto a conductas consideradas graves infracciones al Derecho Internacional Humanitario o graves violaciones de los derechos humanos".

El artículo $7^{\circ}$ transitorio establece que la JEP estará compuesta por los siguientes órganos: 1) El Tribunal para la Paz. Este tribunal "es el órgano de cierre y la máxima instancia de la jurisdicción especial para la paz". El tribunal para la paz se conformará "por dos secciones de primera instancia, una Sección de revisión de sentencias, una Sección de apelación y la Sección de estabilidad y eficacia". Este tribunal se integrará "por un mínimo de 20 magistrados colombianos titulares" y "contará con 4 juristas expertos extranjeros que intervendrán" quienes "participarán en los debates de la Sección en la que se hubiera requerido su intervención, en las mismas condiciones que los magistrados, pero sin derecho de voto". 2) Las salas de reconocimiento de verdad, de responsabilidad y de determinación de los hechos y conductas; de definición de las situaciones jurídicas; y de amnistía o indulto que "estarán conformadas por un total de 18 magistrados colombia- 
nos" y contarán "con 6 juristas expertos extranjeros" quienes participarán en las sesiones sin derecho a voto. 3) La Unidad de investigación y acusación encargada de realizar "las investigaciones correspondientes" y adelantar "el ejercicio de la acción penal ante el Tribunal para la Paz" y 4) la Secretaría ejecutiva. La jurisdicción contará además con un presidente.

Teniendo en cuenta la importancia de este asunto para la configuración de la jurisdicción en Colombia, debe resaltarse que, de acuerdo con el artículo $8^{\circ}$ transitorio, la tutela procede contra las decisiones de los distintos órganos de la JEP. El citado artículo señala que la acción de tutela procede "solo por una manifiesta vía de hecho o cuando la afectación del derecho fundamental sea consecuencia directa por deducirse de su parte resolutiva y se hubieran agotado todos los recursos al interior de la jurisdicción especial para la paz". Además, el artículo $8^{\circ}$ transitorio define que las acciones de tutela "deberán ser presentadas ante el Tribunal para la Paz, único competente para conocer de ellas". En estos procesos de tutela la "primera instancia será decidida por la Sección de revisión" y la segunda instancia "por la Sección de apelaciones". En todo caso, se admite que las sentencias de tutela podrán ser revisadas por la Corte Constitucional siempre que así lo decida "una sala conformada por dos magistrados de la Corte Constitucional escogidos por sorteo y dos magistrados de la jurisdicción especial para la paz". Para que el fallo sea seleccionado, se definió que los cuatro magistrados deben votar "a favor de la selección". La Corte Constitucional, según el artículo $8^{\circ}$ transitorio, revisará las decisiones de la JEP por la Sala plena y en caso de que encuentre que "el derecho invocado ha sido vulnerado, así lo declarará precisando en qué consiste la violación, sin anular, invalidar o dejar sin efectos la decisión del órgano de la jurisdicción especial para la paz".

Siendo conscientes de las complejidades de este asunto y de lo prematuro del desarrollo de la JEP, es posible, de todas maneras, resaltar dos cuestiones que resultan pertinentes para el estudio que estamos presentando en este escrito. En primer lugar, el artículo $8^{\circ}$ transitorio está limitando las competencias de la Corte Constitucional como órgano de cierre de la jurisdicción constitucional en tanto que, primero, le prohíbe declarar nulas o invalidas las decisiones de la JEP y, segundo, le otorga competencias a los magistrados de la JEP para que seleccionen sentencias. En cuanto a lo primero, debe recordarse que la Corte Constitucional tradicionalmente ha entendido que sus competencias como garante de la supremacía de la Constitución incluye la de la potestad de invalidar las normas jurídicas y decisiones que sean contrarias a ella. En cuanto a lo segundo, la selección de sentencias para su revisión es una potestad que hace parte de las competencias exclusivas de la Corte Constitucional definidas en el artículo 241 de la Constitución y que se entienden propias del órgano de cierre de la jurisdicción constitucional. De acuerdo con esto, el artículo $8^{\circ}$ transitorio estaría limitando las competencias de la Corte Constitucional como órgano de cierre y otorgando a los magistrados de 
la JEP tales competencias, pues al establecerse la exigencia de unanimidad, se está estableciendo implícitamente que los magistrados de la JEP tienen la posibilidad de impedir la selección de sus propias decisiones.

En segundo lugar, vale preguntarse si dentro de las causales señaladas está incluida la del desconocimiento de los precedentes constitucionales. Siguiendo la argumentación que tradicionalmente ha efectuado la Corte Constitucional, habría que mencionar que el desconocimiento de sus precedentes en materia de interpretación de los derechos fundamentales es una consecuencia necesaria de su posición de órgano de cierre de la jurisdicción constitucional y de intérprete autorizado de la Constitución. Por lo tanto, al observarse que procede la acción de tutela contra las decisiones de la JEP (lo que quiere decir que queda supeditada a la jurisdicción constitucional como lo están el resto de jurisdicciones) y que la autoridad de la Corte Constitucional (como órgano de cierre de la jurisdicción en Colombia y máximo intérprete de la Constitución) no ha sido modificada, entonces es posible concluir que la doctrina del precedente constitucional, tal y como ha sido desarrollada en el derecho constitucional colombiano, es predicable respecto de las decisiones de la JEP.

\subsection{Las variables vertical y horizontal del precedente constitucional}

La estructura de la jurisdicción es fundamental en la descripción del alcance subjetivo de los precedentes judiciales
(Dobbins, 2010). En virtud de esta estructura, es posible distinguir entre precedente vertical y horizontal. Esta idea ha sido recogida por la Corte Constitucional (en la Sentencia SU-230 de 2015), para quien la distinción planteada depende de:
La jerarquía de la autoridad judi- cial que profiere la providencia previa. El primero hace referencia a aquellas sentencias fijadas por autoridades de la misma jerarquía o el mismo operador judicial, y el segundo se relaciona con los lineamientos sentados por las instancias superiores encargadas de unificar jurisprudencia dentro de la respectiva jurisdicción.

Para dar cuenta de las variables vertical y horizontal del precedente en Colombia, recuérdese que la estructura de la jurisdicción constitucional en Colombia plantea una organización piramidal. En la cúspide de la estructura está la Corte Constitucional. Esto quiere decir que los precedentes de la Corte Constitucional ejercen autoridad vertical respecto de la totalidad de la jurisdicción en Colombia. Sin embargo, dentro de la propia Corte Constitucional se ha establecido una relación de precedente vertical entre la Sala plena y las salas de revisión.

La Sala plena de la Corte Constitucional está integrada por los nueve magistrados que conforman esta corporación (artículo 44, Ley 270 de 1996). A la Sala plena le corresponde proferir dos tipos de sentencias: primero, profiere las sentencias de constitucionalidad abstracta (sentencias tipo C, en la nomenclatura 
de la Corte Constitucional' ${ }^{12}$ ) de las leyes y actos reformatorios de la Constitución. Segundo, profiere las sentencias de unificación (Sentencias SU). Por medio de las sentencias SU, la Sala plena de la Corte Constitucional resuelve asuntos cuando: i) la trascendencia del tema lo amerite, ii) sea necesario unificar jurisprudencia y iii) se vaya a realizar un cambio en los precedentes ${ }^{13}$. Las salas de revisión, por su parte, están conformadas por tres magistrados y se encargan de revisar decisiones judiciales relacionadas con la acción de tutela (artículo 50 del Acuerdo 05 de 1992, Reglamento interno de la Corte Constitucional).

La Corte Constitucional, en desarrollo del artículo 34 del Decreto 2591 de 1991, ha establecido que solo la Sala plena es

12 En lo referente a la nomenclatura de las sentencias, la Corte Constitucional identifica las sentencias de constitucionalidad abstracta con la letra $C$, seguida del número y del año de la sentencia; por su parte, las sentencias de tutela las identifica con las letras T o SU (sentencias de unificación), seguidas por el número y el año de la sentencia.

13 Sobre el particular véanse el artículo 54A del Acuerdo 05 de 1992 y el artículo 34 del Decreto 2591 de 1991. Debe tenerse en cuenta que la unificación de jurisprudencia no se reduce a las sentencias de tutela. De acuerdo con la Corte Constitucional, mediante las sentencias SU debe "unificar jurisprudencia respecto de fallos judiciales proferidos por diferentes jurisdicciones, como resultado de diferentes acciones judiciales, en aquellos casos en que a partir de supuestos fácticos idénticos se produzcan fallos que originen discrepancias capaces de impedir la vigencia o realización de un derecho fundamental" (Corte Constitucional, Sentencia SU- 913 de 2009). Esta doctrina reafirma la tesis de la jurisdicción monista en Colombia presentada en el acápite anterior de este trabajo. competente para cambiar la jurisprudencia y que las salas de revisión están obligadas a seguir los precedentes de la Sala plena (precedente vertical) e, incluso, de las propias salas de revisión (precedente horizontal) $)^{14}$. Al respecto, la Corte Constitucional ha definido dos causales con base en las cuales es posible solicitar la nulidad de las sentencias de las salas de revisión por desconocimiento de precedente. En primer lugar, cuando las salas de revisión se apartan de los precedentes definidos en las sentencias C o SU precedente vertical- En segundo lugar, cuando las salas de revisión desconocen la jurisprudencia en vigor de las mismas salas - precedente horizontal — (Corte Constitucional, Sentencia SU-230 de 2015).

El concepto de jurisprudencia en vigor se refiere a la existencia de un precedente judicial consolidado. Es decir, este tipo de precedente existe en aquellos casos en los que una regla jurídica originada en las decisiones de las salas de revisión es aplicada de forma reiterada y consistente. Así las cosas, y en palabras de la Corte Constitucional, la jurisprudencia en vigor aparece cuando las salas de revisión adoptan "de manera uniforme la misma regla de decisión" (Corte Constitucional, 2014a). De esta manera, la nulidad de las sentencias de las salas de revisión puede ser solicitada cuando se desconoce el precedente vertical (i.e. precedentes de la Sala plena) o cuando se desconoce la jurisprudencia en vigor, es decir "cuando se verifique que la referida línea juris-

14 Corte Constitucional, Autos A-074 de 2010, A-019 de 2011, A-097 de 2011, A-239 de 2012 y A-50 de 2013. 
prudencial sobre un determinado tema es sostenida, uniforme y pacífica" (Corte Constitucional, 2014b).

En todo caso, debe tenerse en cuenta que los precedentes de la Corte Constitucional, sean de la Sala plena o de las salas de revisión, vinculan de forma vertical al resto de la jurisdicción. Esto quiere decir que, tanto los órganos de cierre de la jurisdicción ordinaria (Corte Suprema de Justicia), de la contencioso-administrativa (el Consejo de Estado) y disciplinaria (la Comisión Nacional de Disciplina Judicial), como los tribunales y jueces, están vinculados verticalmente en relación con los precedentes de la Corte Constitucional.

En este orden de ideas, es importante resaltar que la vinculación vertical en relación con los precedentes de la Corte Constitucional, no se refiere exclusivamente a las decisiones de los órganos judiciales en tanto tomen decisiones de tutela. En realidad, en las decisiones que tomen en sus respectivas jurisdicciones, los órganos judiciales (órganos de cierre y de instancia) están vinculados a los precedentes de la Corte Constitucional. Inclusive, y como se explicó más arriba, la Corte Constitucional ha desarrollado la doctrina de la tutela contra sentencias como mecanismo para que las decisiones de las jurisdicciones ordinaria, administrativa y disciplinaria se vinculen a sus precedentes.

\section{CONCLUSIONES}

En los ordenamientos jurídicos es posible diferenciar entre la RP y los PJ. Los PJ son aquellas reglas jurídicas provenientes de una decisión judicial (o de un conjunto de ellas) y que exigen que determinadas conductas o actos deban ser realizados. La RP, por su parte, es una regla secundaria que define los criterios para identificar los PJ autoritativos (i.e. aquellas normas originadas en decisiones judiciales que deben ser aplicadas por los operadores jurídicos) y las formas, procedimientos y competentes para crearlos, modificarlos, derogarlos y aplicarlos. En tanto regla de adjudicación (es decir, en tanto regla secundaria que define los procedimientos, formas y competentes para aplicar PJ), la $\mathrm{RP}$ presenta la siguiente estructura: Al, mediante el procedimiento $\mathrm{P}$, es competente para aplicar PJ.

El ámbito subjetivo de aplicación de la $\mathrm{RP}$ se refiere al conjunto de órganos Al a los que la RPA otorga la competencia para aplicar PJ en el ordenamiento jurídico respectivo. En este contexto se distingue entre precedente vertical —aquellos PJ que provienen de sentencias de un juez o tribunal de jerarquía superior-. precedente horizontal —aquellos PJ que provienen de sentencias de jueces o tribunales de la misma jerarquía-y autoprecedente - los PJ creados por cada juez o tribunal- La diferencia entre esos tipos de precedente depende de la estructura de la jurisdicción y, en consecuencia, de la jerarquía del órgano judicial que crea el precedente en relación con aquel que debe aplicarlo.

En el caso colombiano, en este trabajo se observó que la jurisdicción está constituida por un sistema centralizado y monista 
en el que la Corte Constitucional se instituye como órgano de cierre del sistema judicial en Colombia. Como se señaló en este trabajo, mediante la revisión de las sentencias de tutela (en particular como consecuencia de la procedencia de la tutela contra las decisiones judiciales de las jurisdicciones ordinaria, administrativa, disciplinaria y especial para la paz), la Corte Constitucional se constituye en el órgano de cierre del sistema judicial colombiano. Teniendo en cuenta esta estructura, los precedentes de la Corte Constitucional ejercen autoridad vertical respecto de la totalidad de la jurisdicción en Colombia.

Dentro de la propia Corte Constitucional se han establecido relaciones de precedente vertical y horizontal. En primer lugar, los PJ de la Sala plena ejercen autoridad vertical en relación con las decisiones de las salas de revisión. Y los precedentes consolidados de las salas de revisión ejercen autoridad horizontal en relación con las decisiones de esas salas. Pero, en todo caso, los PJ de la Corte Constitucional (de la Sala plena o de las salas de revisión) ejercen autoridad vertical sobre el resto de la jurisdicción.

Para terminar, es necesario hacer tres comentarios adicionales. En primer lugar, no es del todo claro si existe vinculación vertical de los precedentes en relación con las sentencias de tutela más allá de las sentencias de la Corte Constitucional. La cuestión se refiere a si, por ejemplo, los precedentes de la Corte Suprema de Justicia en materia de tutela vinculan o no a los tribunales y jueces.
En segundo lugar, una explicación exhaustiva de las relaciones vertical y horizontal de los precedentes en la jurisdicción colombiana depende de un estudio detallado de la organización de cada uno de los órganos que conforman la jurisdicción. En este sentido, se hace necesario, por ejemplo, estudiar detalladamente cómo está compuesta la jurisdicción de lo contencioso-administrativo, y así explicar la estructura del Consejo de Estado y el tipo de relaciones que existen entre las diferentes salas que lo componen y los tribunales y jueces que componen esa jurisdicción.

En tercer lugar, y siendo conscientes del incipiente desarrollo de la JEP, a partir de las consideraciones expuestas es necesario subrayar los siguientes asuntos: 1) la estructura y funciones actuales de la JEP están limitando las competencias de la Corte Constitucional como órgano de cierre de la jurisdicción constitucional en tanto a) le prohíbe a la Corte Constitucional declarar nulas o inválidas las decisiones de la JEP y b) otorga competencias a los magistrados de la JEP para que seleccionen sentencias. 2) Una adecuada comprensión del desarrollo de la JEP y su impacto en el modelo de jurisdicción en Colombia dependerá de cómo se resuelva la cuestión acerca de la tutela contra sus decisiones y, en particular, si dentro de las causales reconocidas estará incluida la del desconocimiento de los precedentes constitucionales. Este asunto, por las razones expuestas en este trabajo, será fundamental para la adecuada articulación de la JEP en la jurisdicción colombiana. 


\section{REFERENCIAS}

Alexander, L. (2012). Precedential Constraint, Its Scope and Strength: A Brief Survey of the Possibilities and Their Merits. En C. Bernal y T. Bustamante (Eds.), On the Philosophy of Precedent (PP. 75-82). Stuttgart: Nomos.

Alchourron, C. y Bulygin, E. (1974). Introducción a la metodología de las ciencias jurídicas y sociales. Buenos Aires: Astrea.

Atienza, M. y Ruiz Manero, J. (1996). Las piezas del derecho. Barcelona: Ariel.

Azula, J. (2006). Manual de derecho procesal. Bogotá: Temis.

Barreto, A. (2017). Efectos de la implementación de los acuerdos de paz en la estructura orgánica del Estado: la burocracia de la paz. Precedente. Revista Jurídica, 10, 185-224. Recuperado de https://doi.org/10.18046/ prec.v10.2477

Bernal, C. (2005). El derecho de los derechos. Bogotá: Universidad Externado.

Bronaugh, R. (1987). Persuasive Precedent. En L. Goldstein (Ed.), Precedent in Law (pp. 216-247). Oxford: Clarendon Press.

Dobbins, J. (2010). Structure and Precedent. Michigan Law Review, 108(8), 1453-1496.

Cifuentes, E. (2002). Jurisdicción constitucional en Colombia. Ius et Praxis, 8(1), 283-317.

Congreso de la República. (1992). Ley 5 por la cual se expide el Reglamento del Congreso, el Senado y la Cámara de Representantes. Diario Oficial 40 483, Bogotá.

Congreso de la República. (1996). Ley 270 estatutaria de la administración de justicia. Diario Oficial 42 745, Bogotá.

Congreso de la República. (2015). Acto Legislativo 2 por medio del cual se adopta una reforma de equilibrio de poderes y reajuste institucional y se dictan otras disposiciones. Diario Oficial 49 560, Bogotá.

Congreso de la República. (2016). Acto legislativo 1 por medio del cual se establecen instrumentos jurídicos para facilitar y asegurar la implementación y el desarrollo normativo del acuerdo final para la terminación del conflicto y la construcción de una paz estable y duradera. Diario Oficial 49 927, Bogotá.

Congreso de la República. (2017). Acto legislativol por medio del cual se crea un título de disposiciones transitorias de la Constitución para la terminación del conflicto armado y la construcción de una paz estable y duradera y se dictan otras disposiciones. Diario Oficial 50 196, Bogotá.

Constitución Política de Colombia de 1991.

Corte Constitucional. (1992). Acuerdo 05. Reglamento Interno.

Corte Constitucional (2010). Auto A-074. M.P. Pinilla Pinilla, N.

Corte Constitucional. (2011a). Auto A-019. M.P. Calle Correa, M.

Corte Constitucional. (2011b). Auto A-097. M.P. Sierra Porto, $\mathrm{H}$.

Corte Constitucional. (2012). Auto A-239. M.P. Julio E., A.

Corte Constitucional. (2013). Auto A50. M.P. Pinilla Pinilla, N.

Corte Constitucional. (2014a). Auto A13. M.P. Vargas Silva, L.

Corte Constitucional. (2014b). Auto A290-16. M.P. Rojas Ríos, A.

Corte Constitucional. (2009). Sentencia SU-91309. M.P. Henao Pérez, J. 
Corte Constitucional. (2014c). Sentencia T-102. M.P. Pretelt Chaljub, J.

Corte Constitucional. (2014d). Sentencia T-430. M.P. Rojas Ríos, A.

Corte Constitucional. (2015a). Sentencia T-056. M.P. Sáchica Méndez, M.

Corte Constitucional. (2015b). Sentencia SU-230. M.P. Pretelt Chaljub, J.

Corte Constitucional, (2016a). Sentencia T-096 de 2016. M. P. Vargas Silva, L.

Corte Constitucional. (2016b). Sentencia C-285. M.P. Guerrero Pérez, L.

Cross, R. y Harris, J. (2012). El precedente en el derecho inglés. Madrid: Marcial Pons.

Ferreres, V. (2011). Una defensa del modelo europeo de control de constitucionalidad. Madrid: Marcial Pons.

Ferreres, V. (2005). Las consecuencias de centralizar el control de constitucionalidad de la ley en un tribunal especial. En R. Saba (Ed.), Los límites a la democracia (pp. 305-326). Buenos Aires: Editores del Puerto.

Gascón, M. (2012). Rationality and (Self) Precedent: Brief Considerations Concerning the Grounding and Implications of the Rule of Self Precedent. En C. Bernal y T. Bustamante (Eds.), On the Philosophy of Precedent (pp. 35-50). Stuttgart: Nomos.

Guastini, R. (2001). Estudios de teoría constitucional. Ciudad de México: Fontamara.

Hart, H. L. A. (1994). The concept of law (2. ${ }^{\text {E Ed.). }}$ Oxford: Clarendon Press.

Quinche, M. (2013). El control de constitucionalidad. Bogotá: Editorial Universidad del Rosario.

Levenbook, B. (2000). The Meaning of a Precedent. Legal Theory, 6(2), 185-240.
Lamond, G. (2014). Precedent and Analogy in Legal Reasoning. En E. Zalta (Ed.), The Stanford Encyclopedia of Philosophy. Recuperado de http://plato.stanford.edu/archives/spr2014/ entries/legal-reas-prec/

MacCormick, N. y Summers, R. (1997). Introduction. En N. MacCormick y R. Summers (Eds.), Interpreting Precedents (pp. 1-15). Aldershot: Ashgate/Dartmouth.

Magaloni, A. (2001). El precedente constitucional en el sistema judicial norteamericano. Madrid: McGraw-Hill Interamericana de España.

Moreso, J. y Vilajosana, J (2004). Introducción a la teoría del derecho. Madrid: Marcial Pons.

Presidencia de la República de Colombia. (1991). Decreto 2591 por el cual se reglamenta la acción de tutela consagrada en el artículo 86 de la Constitución Política. Diario oficial 40 165, Bogotá.

Pulido, F. (2015). Jurisdicción constitucional en Colombia: ¿un modelo monista? En L. Castillo Córdova (Ed.), ¿Son anulables las sentencias del tribunal constitucional? (pp. 81-105). Lima: Palestra Editores.

Pulido, F. (2016). Los criterios de validez jurídica: incógnitas para la implementación de los acuerdos de paz. En G. Eljach, J. Castrillón y G. Niño (Eds.), La Paz, el derecho de la democracia (pp. 402-414). Bogotá: Editorial Universidad del Cauca.

Pulido, F. (2018). Jueces y reglas: la autoridad del precedente judicial. Bogotá: Universidad de La Sabana.

Taruffo, M. (1997). Precedent in Italy. En N. MacCormick y R. Summers (Eds.), Interpreting Precedents (pp. 437-460). Aldershot: Ashgate/ Dartmouth.

Von Wright, G. (1963). Norm and Action: A Logical Inquiry. Londres: Routledge and Kegan Paul. 